\title{
Tracheal intubation with rocuronium using a "modified timing principle"
}

\author{
Min A Kwon, Jaegyok Song, and Ju-Ri Kim \\ Department of Anesthesia and Pain Medicine, College of Medicine, Dankook University, Cheonan, Korea
}

Background: Rapid sequence induction (RSI) is indicated in various situations. Succinylcholine has been the muscle relaxant of choice for RSI, and rocuronium has become an alternative medicine for patients who cannot be administered succinylcholine for various reasons. Although rocuronium has the most rapid onset time among nondepolarizing muscle relaxants, the standard dose of rocuronium $(0.6 \mathrm{mg} / \mathrm{kg})$ takes 60 seconds to achieve appropriate muscle relaxation. We evaluated intubating conditions using the "modified timing principle" with rocuronium and succinylcholine.

Methods: In this prospective controlled blinded study, all patients received $1.5 \mu \mathrm{g} / \mathrm{kg}$ fentanyl intravenously with preoxygenation for 2 minutes and were randomized to receive $0.6 \mathrm{mg} / \mathrm{kg}$ rocuronium followed by $1.5 \mathrm{mg} / \mathrm{kg}$ propofol or $1.5 \mathrm{mg} / \mathrm{kg}$ propofol and $1.5 \mathrm{mg} / \mathrm{kg}$ succinylcholine. The rocuronium group was intubated just after confirming loss of consciousness, and the succinylcholine group was intubated 1 minute after injecting succinylcholine. Intubation condition, timing of events, and complications were recorded.

Results: All patients were successfully intubated in both groups. Apnea time of the rocuronium group (38.5 seconds) was significantly shorter than that in the succinylcholine group (100.7 seconds). No significant differences were observed in loss of consciousness time or intubation time. The succinylcholine group tended to show better intubation conditions, but no significant difference was observed. None of the patients complained awareness of the intubation procedure or had respiratory difficulty during a postoperative interview.

Conclusions: The modified RSI with rocuronium showed shorter intubation sequence, acceptable intubation conditions, and a similar level of complications compared to those of conventional RSI with succinylcholine. (Korean J Anesthesiol 2013; 64: 218-222)

Key Words: Intratracheal, Intubation, Rocuronium, Succinylcholine.

Received: August 10, 2012. Revised: September 16, 2012. Accepted: September 18, 2012.

Corresponding author: Jaegyok Song, M.D., Department of Anesthesia and Pain Medicine, College of Medicine, Dankook University, San 16-5, Anseo-dong, Dongnam-gu, Cheonan 330-714, Korea. Tel: 82-41-550-6819, Fax: 82-41-550-6819, E-mail: drjack@nate.com

(C) This is an open-access article distributed under the terms of the Creative Commons Attribution Non-Commercial License (http:// creativecommons.org/licenses/by-nc/3.0/), which permits unrestricted non-commercial use, distribution, and reproduction in any medium, provided the original work is properly cited. 


\section{Introduction}

Rapid sequence induction (RSI) is indicated under conditions of an increased risk of gastric content aspiration, such as a full stomach, an intestinal obstruction, and general anesthesia for caesarean section [1]. Succinylcholine has been the drug of choice for muscle relaxation during RSI, and rocuronium has become an alternative medicine for patients who cannot be administered succinylcholine for various reasons. Although rocuronium has the most rapid onset time among nondepolarizing muscle relaxants (NDMRs), the standard rocuronium dose $(0.6 \mathrm{mg} /$ $\mathrm{kg}$ ) takes 60 seconds to achieve appropriate muscle relaxation. Several options are available to decrease rocuronium onset time such as increasing the dose $(1-1.2 \mathrm{mg} / \mathrm{kg})$ and various timing principles [1-4]. The "timing principle" involves administering an intubating dose of the NDMR before induction of general anesthesia to allow a sufficient time interval between the NDMR injection and endotracheal intubation [4]. This procedure can also considerably decrease the interval between loss of consciousness and endotracheal intubation. Sieber et al. [1] injected rocuronium $(0.6 \mathrm{mg} / \mathrm{kg})$ and observed patient muscle relaxation signs (ptosis) and then injected thiopental. The patients were intubated 45-60 seconds after the thiopental injection. Nelson et al. [3] used another timing principle. They injected rocuronium $(0.6 \mathrm{mg} / \mathrm{kg})$ and thiopental was injected 20 seconds later, followed by endotracheal intubation 60 seconds after the thiopental injection. Many studies about RSI have been conducted with rocuronium, and all "waited 40-60 seconds" after administering the neuromuscular blocking agent until full relaxation was achieved. We always preoxygenate patients with $100 \% \mathrm{O}_{2}$ for $2-3$ minutes before RSI, but arterial hypoxemia may occur occasionally during the "waiting time". Given the current emphasis on evidence-based medicine, it seems poor practice to follow a tradition blindly. Thus, we modified the timing principle proposed by Nelson et al. [3] The hypnotic agent (propofol) was injected just after injecting rocuronium and endotracheal intubation was performed immediately after loss of consciousness without any predetermined time interval. In a prospective, randomized trial, we evaluated the intubating conditions of RSI using a "modified timing principle" with rocuronium and succinylcholine.

\section{Materials and Methods}

We obtained written, informed consent from each of 40 American Society of Anesthesiologists (ASA) physical status I or II patients (age range, 18-70 yr) undergoing elective surgery. This study was approved by our Institutional Review Board. Exclusion criteria were increased risk of pulmonary aspiration, neuromuscular disease, medications that could influence neuromuscular function, history or anticipation of a difficult airway, and succinylcholine contraindications.

A power analysis revealed that 19 patients were required in each group to detect a difference in intubation condition (proportional difference of "acceptable" condition was $>30 \%$ ) with a power $>90 \%$ and a level of significance of 0.05 . Thus, we enrolled 20 patients per group to account for protocol violations.

Routine monitoring was used. The effect of the muscle relaxant was measured using accelerography (TOF-Watch ${ }^{\circledR}$; Organon Ireland Limited, Swords, Ireland). The bispectral index (BIS) was also monitored. We informed the patients that they might feel weakness or blurred vision before loss of consciousness. No premedication was administered. Patients were randomly assigned to receive rocuronium (group l) or succinylcholine (group 2). Intubations were performed by one of two different anesthesiologists who had no preference for any muscle relaxant to minimize bias. Both groups received 1.5 $\mu \mathrm{g} / \mathrm{kg}$ fentanyl and were preoxygenated with $100 \%$ oxygen for 2 minutes.

Group 1 patients received $60 \mathrm{mg}$ lidocaine and $0.6 \mathrm{mg} / \mathrm{kg}$ rocuronium. We asked the patients to keep their eyes open until they lost consciousness. Propofol ( $1.5 \mathrm{mg} / \mathrm{kg}$ ) was administered intravenously immediately after administering the rocuronium. Train-of-four (TOF) monitoring was initiated upon loss of the eyelid reflex and just after intubation. Routine direct laryngoscopy and tracheal intubation were performed after loss of the eyelid reflex and loss of a response to verbal commands by an experienced anesthesiologist who was blinded to the anesthetic drug.

Group 2 patients received $60 \mathrm{mg}$ lidocaine and $1.5 \mathrm{mg} / \mathrm{kg}$ propofol. Succinylcholine $(1.5 \mathrm{mg} / \mathrm{kg})$ was administered after loss of the eyelid reflex and loss of response to verbal commands. Routine direct laryngoscopy and tracheal intubation were performed 60 seconds after administering succinylcholine [5]. TOF monitoring was not performed in group 2.

Endotracheal intubations were performed using a Macintosh \# 3 blade and a tracheal tube with an internal diameter of 7.5 $\mathrm{cm}$ for men and $7.0 \mathrm{~cm}$ for women. The timing of events was recorded by the anesthetic nurse. The "apnea time" was defined as the time interval between the propofol injection and the first appearance of end-tidal $\mathrm{CO}_{2}$. The "loss of consciousness time" was defined as the time interval between propofol injection and loss of eyelid reflex and loss of response to verbal commands. The "intubation time" was defined as the time interval during which intubation was performed.

We evaluated intubation condition with the scoring system of Sluga et al. [2] Intubation conditions were evaluated using the following factors: (a) ease of laryngoscopy (jaw relaxation and resistance to laryngoscope insertion), (b) position and 
Table 1. Scoring System for Endotracheal Intubation Conditions

\begin{tabular}{llll}
\hline & Score 3 & Score 2 & Score 1 \\
\hline $\begin{array}{l}\text { Laryngoscopy } \\
\text { Mandibular muscle relaxation }\end{array}$ & Relaxed & Acceptable relaxation & Poor relaxation \\
$\begin{array}{l}\text { Resistance to blade insertion } \\
\text { Vocal cords }\end{array}$ & None & Slight resistance & Active resistance \\
$\begin{array}{l}\text { Position } \\
\text { Movement }\end{array}$ & Abducted & Intermediate & Closed \\
Intubation response & None & Moving & Closing \\
Limb movement & None & Slight & Vigorous \\
Coughing & None & Diaphragmatic & Severe coughing or bucking \\
\hline
\end{tabular}

The factors laryngoscopy, vocal cords, and intubation response were rated with a scoring system from 1 to 3 . For example, mandibular muscle relaxed (score 3) and resistance to blade (score 2) results in a score of 2 for the laryngoscopy. Intubation conditions were defined as follows: excellent, all three factors were rated 3 good, all three factors were rated 3 or 2 poor, the presence of one score of 1 .

Table 2. Patient Demographics

\begin{tabular}{lcc}
\hline & $\begin{array}{c}\text { Rocuronium } \\
(\mathrm{N}=20)\end{array}$ & $\begin{array}{c}\text { Succinylcholine } \\
(\mathrm{N}=20)\end{array}$ \\
\hline Age $(\mathrm{yr})$ & $40.9 \pm 6.3$ & $45.6 \pm 10.4$ \\
Sex $(\mathrm{M} / \mathrm{F})$ & $3 / 17$ & $3 / 17$ \\
ASA $(\mathrm{I} / \mathrm{II} / \mathrm{III})$ & $17 / 3 / 0$ & $15 / 5 / 0$ \\
Height $(\mathrm{cm})$ & $161.5 \pm 7.9$ & $160.3 \pm 7.0$ \\
weight $(\mathrm{kg})$ & $61.8 \pm 13.2$ & $60.1 \pm 11.9$ \\
\hline
\end{tabular}

Mean \pm standard deviation. No significant differences were observedbetween the groups. ASA: American Society of Anesthesiologists physical status.

movement of the vocal cords, and (c) response of the diaphragm and limbs to intubating the airway. The anesthesiologist who performed the intubation rated these variables (Table 1).

Arterial oxygen desaturation was defined as saturation $<90 \%$ occurring at any time from induction to 2 minutes after completing the intubation. Significant blood pressure changes after intubation were defined as mean arterial pressure changes $>20 \%$.

All patients were interviewed by a blinded investigator 6-24 $\mathrm{h}$ after surgery. Three questions were asked: 1 . Did you feel weakness or blurred vision just before going to sleep? 2. Did you feel shortness of breath just before going to sleep? 3. Can you recall any discomfort during anesthesia (For example; awareness during anesthetic induction or injection pain) and after surgery. Injection pain was graded I to IV (grade I: visual analog scale [VAS] score, $0-2$, grade II: VAS, $3-4$, grade III: VAS, $5-6$, grade IV: VAS, $>7$ ).

Data are presented as mean \pm standard deviation. SPSS 12.0 for Windows (SPSS, Chicago, IL, USA) was used for the analysis. Patient data were compared by analysis of variance, the chisquare test, Fisher's exact test, and Kruskal-Wallis test, as appropriate. A P $<0.05$ was considered significant.
Table 3. Intubation Conditions

\begin{tabular}{lcc}
\hline & $\begin{array}{c}\text { Rocuronium } \\
(\mathrm{N}=20)\end{array}$ & $\begin{array}{c}\text { Succinylcholine } \\
(\mathrm{N}=20)\end{array}$ \\
\hline Unconsciousness time (sec) & $22.9 \pm 5.3$ & $24.8 \pm 5$ \\
Intubation time (sec) & $15.2 \pm 4.6$ & $15.9 \pm 4.2$ \\
Apnea time (sec)* & $38.5 \pm 7.6$ & $100.7 \pm 7.3$ \\
$\quad$ Maximum/Minimum & $56 / 28$ & $117 / 84$ \\
Intubation condition & & \\
$\quad$ Intubation score & $7.9 \pm 0.6$ & $8.3 \pm 1.0$ \\
Excellent/Good & $5 / 12$ & $11 / 7$ \\
Acceptable (Excellent + Good) & 17 & 18 \\
Poor & 3 & 2 \\
TOF & $20 / 0 / 0 / 0$ & - \\
Just before intubation & & \\
$\quad$ (4/4, 3/4, 2/4, 1/4) & $4 / 10 / 5 / 1$ & - \\
Just after intubation & & \\
$\quad$ (4/4, 3/4, 2/4, 1/4) & & \\
BIS & & \\
Before induction & $94.9 \pm 1.7$ & $93.6 \pm 2.3$ \\
Just before intubation* & $83.4 \pm 2.5$ & $44.8 \pm 10.1$ \\
Just after intubation* & $56.9 \pm 7.8$ & $44.7 \pm 11.7$ \\
MAP/HR & & \\
No change (less than 20\%) & $9 / 12$ & $12 / 7$ \\
Increase more than $20 \%$ & $4 / 8$ & $5 / 12$ \\
Decrease more than $20 \%$ & $7 / 1$ & $6 / 1$ \\
\hline
\end{tabular}

Values are mean \pm standard deviation. TOF: Train of four, BIS: Bispectral Index, MAP: Mean arterial pressure, HR: Heart rate. ${ }^{*} \mathrm{P}<0.05$.

\section{Results}

No significant differences were observed in the demographic data between the two groups (Table 2). Tracheal intubation was successful in all patients in both groups. Apnea time in the rocuronium group was significantly shorter than that in the succinylcholine group using the conventional method (Table 3). No significant differences were observed for loss of consciousness or intubation times. The succinylcholine group tended to show better intubation conditions, but no significant difference was observed between the two groups 
(Table 3). The succinylcholine group had a higher rate of grade I, and the rocuronium group had a higher rate of grade II for intubation condition. Thus, the overall "acceptable intubation condition" did not differ significantly between the two groups. The rocuronium group had a significantly higher rate of diaphragmatic contraction than that in the succinylcholine group .

The mean time interval between rocuronium injection and completion of intubation was $50.75 \mathrm{sec}$. The rocuronium group showed a significantly higher BIS score during the intubation phase, but none of the patients reported awareness of the intubation procedure or respiratory difficulty at the postoperative interview. The rocuronium group tend to have more mean arterial blood pressure changes and the succinylcholine group tended to show more heart rate changes, but the differences were not significant (Table 3). No significant oxygen desaturation was observed in either group. Three patients in the rocuronium group complained of grade III injection pain (grade I, 11 patients; grade II, 8 patients). The postoperative interview revealed no significant findings.

\section{Discussion}

The aim of the present study was to examine whether a "modified timing principle" method using rocuronium would result in an "acceptable" intubation condition such as with succinylcholine. Perry et al. [6] reported that succinylcholine resulted in better intubation conditions than that in a rocuronium group but no difference was observed when succinylcholine was compared to $1.2 \mathrm{mg} / \mathrm{kg}$ rocuronium in their Cochrane review. We attempted to determine how to decrease the apnea time to less than 1 minute using rocuronium instead of succinylcholine. We confirmed that $0.6 \mathrm{mg}$ rocuronium using a modified timing principle showed acceptable intubation conditions and shorter apnea time. Succinylcholine resulted better intubation conditions, as in a previous study, but the overall success rate was similar to that of rocuronium group [2,7]. However, succinylcholine can have serious side effects and is contraindicated for many conditions. Moreover, mouth opening is difficult in the first minute after injecting succinylcholine as a result of the depolarizing effect of the drug. We can wait one minute for full relaxation for most RSI. However, if a critical patient must be intubated quickly and the intubation condition is acceptable, why do we need full relaxation? Some reports are available about acceptable intubation conditions with the use of propofol and alfentanil without muscle relaxants $[8,9]$. Nelson et al. [3] reported successful RSI using a modified RSI timing principle $(0.6 \mathrm{mg} / \mathrm{kg}$ rocuronium was administered 20 seconds before thiopental) and reported that even when a nerve stimulator is used for guidance, intubation is often carried out at less than $100 \%$ neuromuscular blockade. We agree with their opinion that "cadaveric" paralysis is unnecessary for safe tracheal intubation under many situations.

Mean apnea time was 100.7 seconds, and the maximum time was 117 seconds in the succinylcholine group. Arterial oxygen saturation $\left(\mathrm{SaO}_{2}\right)$ will decrease to $90 \%$ within 1 minute if preoxygenation is inadequate [10]. $\mathrm{SaO}_{2}$ will decrease to $90 \%$ within 2 minutes and 30 seconds even with preoxygenation in patients who are vulnerable to hypoxemia. Concomitantly administered anesthetics may decrease the time to hemoglobin desaturation even more [10]. If the patient is a healthy young adult with adequate preoxygenation, there is no need to rush. However, faster is better in patients susceptible to hypoxemia (morbid obesity, infant, body weight $<10 \mathrm{~kg}$, high risk of aspiration pneumonia, or severe hypoxemia with difficult mask ventilation). In this regard, this modified timing principle can be an option.

We do not wait an additional 20 seconds after administering rocuronium, and patient consciousness can be verified after administration of a predetermined propofol dose before full relaxation, which decreases the risk of awareness during induction.

Marsh et al. [11] reported that rocuronium and succinylcholine groups have similar intubation conditions and a similar risk of intubation-related complications. In contrast to the present study, their mean intubation sequence was 14 seconds shorter after succinylcholine than that after rocuronium. The difference is that they injected succinylcholine just after injecting propofol without confirming loss of consciousness and intubated the patient 45 seconds after injecting succinylcholine or after loss of lower limb fasciculation. This method of using succinylcholine may increase the risk of an undesirable experience during induction of anesthesia.

In the present study, the BIS score began to decrease after loss of the eyelid reflex, and intubation was performed before the score reached the lowest point. Although the mean BIS score when attempting a direct laryngoscopy was 83.4, no patient complained of awareness during induction of anesthesia.

A limitation of this trial was that we only used fentanyl and propofol as induction agents; thus, the findings cannot be extrapolated to other drugs and/or doses. We did not experience severe hypotension or bradycardia during this study performed on ASA I or II patients, but induction with propofol and fentanyl can induce severe hypotension in critically ill patients. Thus, this method should be used with caution in such patients.

In conclusion, the results demonstrate that 1) intubation condition was better in the succinylcholine group but was acceptable in the rocuronium group; 2) using the modified timing principle in the rocuronium group markedly reduced the length of the intubation sequence; 3 ) the success rate of 
intubation and intubation-related complications were not different between the two groups. In summary, a modified timing principle using rocuronium can be an acceptable alternative RSI method.

\section{References}

1. Sieber TJ, Zbinden AM, Curatolo M, Shorten GD. Tracheal intubation with rocuronium using the "timing principle". Anesth Analg 1998; 86: 1137-40.

2. Sluga M, Ummenhofer W, Studer W, Siegemund M, Marsch SC. Rocuronium versus succinylcholine for rapid sequence induction of anesthesia and endotracheal intubation: a prospective, randomized trial in emergent cases. Anesth Analg 2005; 101: 1356-61.

3. Nelson JM, Morell RC, Butterworth JF 4th. Rocuronium versus succinylcholine for rapid-sequence induction using a variation of the timing principle. J Clin Anesth 1997; 9: 317-20.

4. Suzuki T, Aono M, Fukano N, Kobayashi M, Saeki S, Ogawa S. Effectiveness of the timing principle with high-dose rocuronium during rapid sequence induction with lidocaine, remifentanil and propofol. J Anesth 2010; 24: 177-81.

5. El-Orbany M, Connolly LA. Rapid sequence induction and intu- bation: current controversy. Anesth Analg 2010; 110: 1318-25.

6. Perry JJ, Lee JS, Sillberg VA, Wells GA. Rocuronium versus succinylcholine for rapid sequence induction intubation. Cochrane Database Syst Rev 2008: CD002788.

7. Mencke T, Knoll H, Schreiber JU, Echternach M, Klein S, NoeldgeSchomburg G, et al. Rocuronium is not associated with more vocal cord injuries than succinylcholine after rapid-sequence induction: a randomized, prospective, controlled trial. Anesth Analg 2006; 102: 943-9.

8. Scheller MS, Zornow MH, Saidman LJ. Tracheal intubation without the use of muscle relaxants: a technique using propofol and varying doses of alfentanil. Anesth Analg 1992; 75: 788-93.

9. Davidson JA, Gillespie JA. Tracheal intubation after induction of anaesthesia with propofol, alfentanil and i.v. lignocaine. Br J Anaesth 1993; 70: 163-6.

10. Benumof JL, Dagg R, Benumof R. Critical hemoglobin desaturation will occur before return to an unparalyzed state following $1 \mathrm{mg} / \mathrm{kg}$ intravenous succinylcholine. Anesthesiology 1997; 87: 979-82.

11. Marsch SC, Steiner L, Bucher E, Pargger H, Schumann M, Aebi $\mathrm{T}$, et al. Succinylcholine versus rocuronium for rapid sequence intubation in intensive care: a prospective, randomized controlled trial. Crit Care 2011; 15: R199. 